LA PARADOJA

La misma encuesta de crédito bancario del Banco Central de Chile de junio 2012 muestra por el lado de la demanda que los agentes están pidiendo más crédito. Es como si ellos no consideraran los riesgos y vivieran una suerte de sobreoptimismo sobre el destino de esta.

Estudios recientes de la economía chilena señalan que los periodos de expansión economica gatillan en el mediano plazo aumentos de la cartera vencida, y luego siduciones de credt to. Este fenómeno ha de riesgo de crédito del sector privado. De manera similar los periodos de covacioción económica, caracterizados especialmente por tasas de interés altas, son seguidos por caidas de mediano plazo de la cartera vencida y, luego, por expansiones del crédito. Es decir, al contrario de una expansión, los agentes económicos se vuelven más pesimistas y toman menos riesgo.

Es interesante reconocer que existe una amplia literatura que ha investigado las

posibilidades de sobreoptimismo en los
agentes económicos. Por ejemplo, algunos derado puede explicar el comportamiento de decisiones financieras. Además, se los hombres son más confiados que las mujeres También que el exceso de sobre optimismo de los CEO puede explicar distorsión de sobreinversión en tiempos de expansión económica. Otros estudios ind can que la sobreconfianza de los agentes puede producir grandes diferencias sobre los verdaderos precios de los activos financieros. Por ejemplo, argumentan que estos comportamientos están en la raiz misma del comportamiento humano: asi la mayoría de las personas se clasifica a si mism

En resumen, se podría estar gestando la tormenta perfecta en el escenario econodeteriorándose cada vez más, un sistema financiero que empieza a desconfiar de la economía y familias y empresas que se sobreendeudan. Todos estos elementos pueden provocar que, en la medida que se cristalice el peor de los escenarios, aterrizaje de la economía sea forzoso y no suave para el 2013.

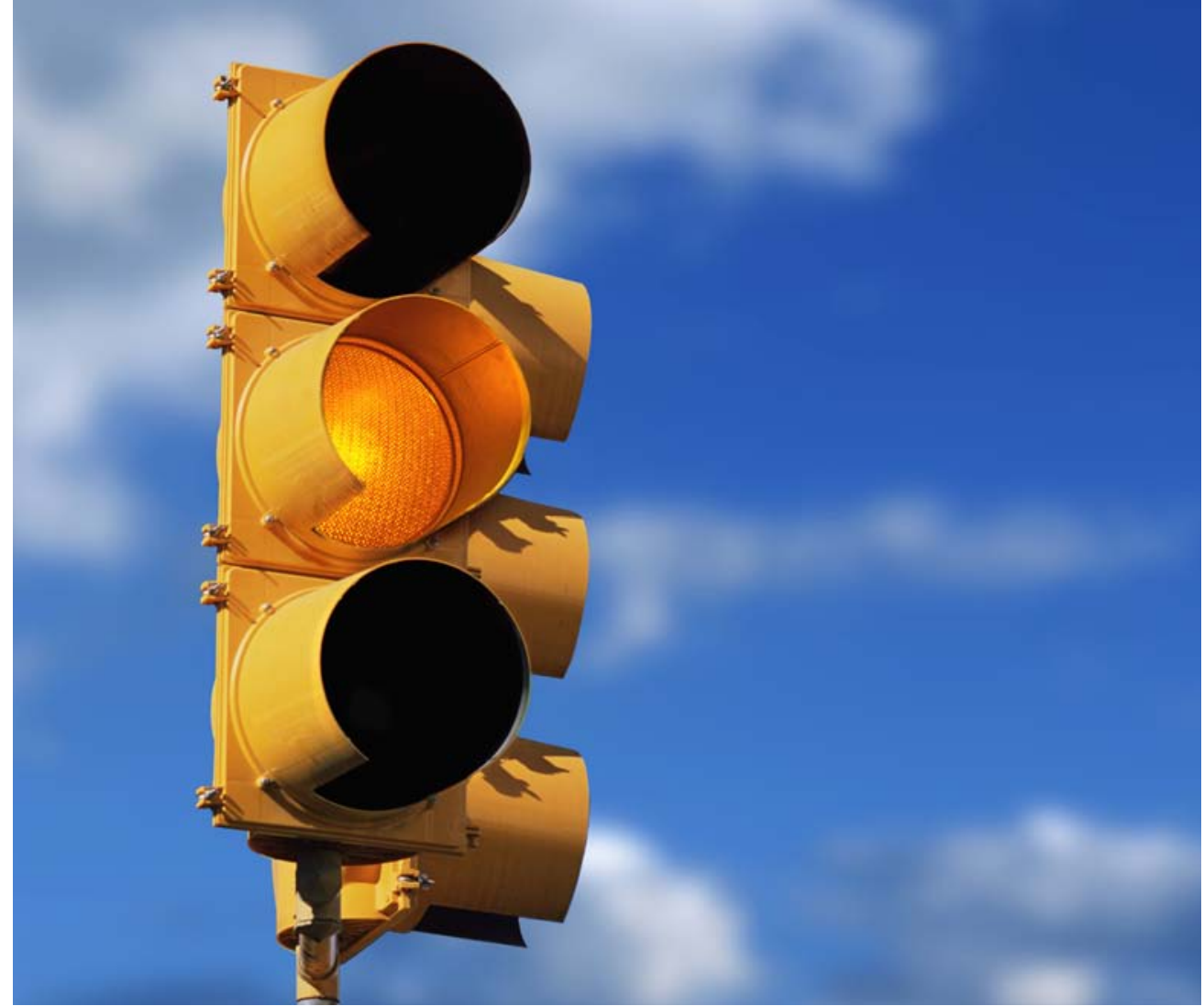

\section{Luz Amarilla en los gobiernos corporativos}

Doctor (Ph.D.) en Economia de Cornell Univers
y Negocios de la Universidad Alberto Hurtado.

Un aumento de capital de una socie- El riesgo de este tipo de comportadad anonima abierta (Enersis) por la vía miento es la otra cara de la moneda de de incluir activos a un valor de mercado los benefios que tiene la concentración compañi con el severo riesgo de que decisiones de su plana gerencill. Este se esos activos estén sobrevalorados y como manifiesta en que el control con Lentrado consecuencia signifiquen una caida en el crea espacios para la obtención de rentas valor de las acciones en general-, genera oportunistas de los grandes accionistas a un claro beneficio a quien aumenta capi- costa de herir los intereses de inversionistal con este mecanismo (Endesa-España) tas pequeños y de los institucionales, tal a costa de los demás accionistas que de- como lo ejemplifica el intento de aumento ben enfrentar una pérdida en exactamen- de capital de Endesa-España en Enersis via te el valor del sobreprecio de los activos activos de dudoso valor real y esperando (inversionistas institucionales como AFP e con ello un aumento proporcional de los inversionistas minoritarios). demás accionistas en activos más liquidos.
El riesgo de expropiación de rentas de estas compañías.

en contra de sus socios no solo significa un traspaso de rentas desde pequeños inversionistas (y desde los trabajadores de pais hacia la trasnacional controladora de Enersis), sino que además, daña la confianza en el funcionamiento del mercado de capitales y genera incentivos perversos en el emprendimiento y a la hora de invertir en el pais. Es por este segundo motivo que la regulacion de los gobiernos corporativos se hace relevante y pertinente en una economía moderna; no solo por
el adecuado manejo de los problemas de trantory los financistas externos de la empresa, sino primordialmente por el contro y adecuado cuidado de la fe pública en proceso de financiamiento de las inversiones con inversionistas que comparten los mismos riesgos que los controladores de esas empresas.

La pregunta es si estas situaciones so "pan de cada día" o más bien corresponde a una situación puntual adecuadamente controlada por la regulación vigente y rol asignado a los directores de las sociedades anónimas. Pareciera que, esta vez, son un hecho puntual, pero no controlado por el gobierno corporativo de esa socireguno que buqueado por la decision de y Seguros) de apuntar que se trataba de y das que requeriría de procedimientos más estrictos para su aprobación definitiva. Es más, la SVS recientemente ha planteado necesidad de normar con más celo el funcionamiento de los gobiernos corporativos de estas sociedades, precisamente hacién dose eco de los reclamos ante la molestia pública por el affair Enersis. Llama la atención que la SVS plantee normas que van mucho más allá de su rol de garante de fe pública implicada en el proceso de oferta de acciones, pues ha planteado incluso
normar la autoevaluación de los directores
En mi parecer, cambios a la normativa cionte deberian apuntar en tres direccasos de claro periuicio a los demás inverpor los controladores veventualmente la plana ejecutiva de las 政 a de sus socios mino-

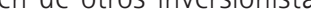
de las sociedades anónimas, como, por ejmio acreedores de deuda. Segundo sos para las penas y aumentar los recurcos uso de cos además de los accionistas controladores incurren directores no controladores pero con intereses en el negocio de corretapreclara el proceder de las transferencias entre partes relacionadas imponiendo umbrales críticos respecto del tamaño de estas transferencias para asi dar certez jurídica a todos los inversionistas en el mercado de capitales.

Por ello, apuntar a normar procedimientos estandarizados como el de autoevaluación de los directores significarta moverse hacia una cogestión de los anónimas, tarea que parece condenada al fracaso por la falta de consenso hacia ese modelo y por la imposibilidad práctica de que procedimientos estandarizados puedan ser adecuadamente controlados cuando este tipo de normas dejan espacio al comportamiento oportunista, imponen todo el costo a los directores e inversionistas honestos que ven cómo la acción regulatoria significa un mayor peso en términos de tiempo dedicados a cumplir a norma, mientras otros podrian saltarla sin riesgo de ser detectados. Peor aún una norma asi traspasaria la responsabilidad del adecuado funcionamiento de los gobiernos corporativos de las empresas cuencio ciertamente indeseada por quie- nes han propuesto la norma.

¿Qué podemos esperar, entonces, del uncionamiento de los gobiernos corpoativos de nuestras sociedades anónimas? s claro que los directores minoritarios -sean representantes de inversionistas insticionales o privados no controladopor Endesa-España con Enersis. No obstante, ello no les exime de la responsabilidad de su decisión, pues podrian oponerse esas estrategias cuando haya indicios clartras que se podría estar actuando en sentan Asi por ejemplo, los inversivepreinstitucionates deberian exigir peritas indenendientes $y$ contrastarlos con los del accionista mayoritario, independientemente de los procedimientos que exías el regulador respecto de las transferencias con empresas relacionadas.

El caso Enersis deja en claro que no suficiente el rol de los directores que repues estos siguen teniendo menos informalion que las controladores respecto a valor de los activos. Precisamente por es ssimetria de información que puede faciarion dor deberi mortarios es que el regulacor deberia establecer como obligatorio enter periaje independiente en la valoracion sociedades anónimas abiertas.

Esto es muy importante tratándose de controladores extranieros cuyas matrices podrian usar estas estrategias para hacer frente a crisis económicas en sus propios paises.

Decano: Jorge Rodríguez Grossi. Fono Facultad: 8897366 e-mail: jrodrigu@uahurtado.cl Producción OE: Comunicar, Escuela de Periodismo UAH. 